\title{
SOBRE PRÁTICA E PONTO DE VISTA PRÁTICO EM MARX
}

\author{
José Crisóstomo de Souza*
}

\begin{abstract}
O texto aborda as noções de prática e materialismo prático em Marx em uma relação de aproximação e distinçã̃o com as concepções do pragmatismo clássico norte-americano, a partir das Teses ad Feuerbach e da Ideologia Alemã, de Marx, e de formulações de Peirce, James e Dewey. De um lado, destaca a fecundidade da noção marxiana de prática e realidade como atividade sensível para uma interpretação renovada de noções como realidade, objetividade e conhecimento, e, de outro, chama a atenção para possíveis elementos essencialistas e transcendentalizantes no pensamento de Marx, que marcariam negativamente o conjunto de sua obra.

PaLAVRAs-CHAVE: Materialismo prático. Pragmatismo. Atividade sensível. Realidade. Conhecimento.
\end{abstract}

Com a expressão filosofia da práxis refiro-me não só ao marxismo ocidental mas também ao pragmatismo norte-americano. Habermas

Neste texto, examino a centralidade e a utilização da noção de atividade prática nas Teses ad Feuerbach, de Marx, de 1845, com alusões também à Ideologia Alemã, de 1845-46, onde ele trata dessa noção junto com outras, correlatas, que a cercam. Chamo o ponto de vista de Marx a respeito, nessas duas fontes, de materialista práticonormativo, enquanto ele próprio prefere "materialismo prático" e, como sinônimo, "comunismo" (sic) - dois aspectos que justamente procuro combinar na denominação por mim sugerida. Entendo que é esse ponto de vista que Marx (1818-1883) sustenta na sua concepção histórica geral, bem como na sua crítica da economia política, embora eu não vá aqui me ocupar de nenhuma das duas detidamente. Neste texto, escolhi esclarecer e comentar as implicações da noção marxiana de ativi-

\footnotetext{
*Doutor em Filosofia. Professor do Depto. de Filosofia da Universidade Federal da Bahia.

Estrada de São Lázaro, 197. Federação. 40240-730. Salvador, Bahia - Brasil. jose_crisostomo@uol.com.br
}

dade prática sensível por uma aproximação de seu materialismo prático (em que ocupa lugar central) ao pragmatismo, com o qual, segundo meu entendimento, ele guarda pontos de contato tanto quanto diferenças essenciais que constituiriam seu viés transcendentalizante.

Como proponho, o materialismo práticonormativo de Marx, nas Teses (e na Ideologia Alemã), pode ser lido como compreendendo seis momentos que se interpenetram e articulam, sempre em torno da noção de prática e realidade como atividade sensível: 1) uma recusa do "empirismo dogmático", "positivista”, intuicionista-passivo, mentalista-cartesiano, bem como do alegadamente impotente idealismo subjetivo; 2) uma superação da concepção do mundo e do sujeito como estáticos, exteriores um ao outro, e, logo, possivelmente, o abandono do ponto de vista do "espectador" e de fixação objetivista-representacionista do real; 3) uma desqualificação do indivíduo "abstrato" da percepção empirista britânica como "robinsonada": a ficção do indivíduo como dissociado-descontextualizado - do "conjunto das relações sociais" e de uma "forma de vida social determinada" ou "modo de vida" 
(Lebensweise); 4) uma crítica do real social como essencialmente cindido, hierarquizado e atomizado pelas "más" relações e práticas sociais imperantes, fundantes ou fundamentais, em que os homens são postos por sua prática, que acarretariam o desdobramento ou duplicação do mundo também no plano do conhecimento e do pensamento, na religião e na filosofia; 5) essa crítica é sustentada justamente pela dedução ou construção de um fundamento forte, de fundo, intramundano mas "essencializado", que determina, por necessidade, o rumo da supressão prática da contradição e a restauração (reconciliação) da unidade-solidariedade social "perdida", com o fim da "autoalienação do homem" - para além do ponto de vista da Sociedade Civil Burguesa de hoje, rumo à Sociedade Humana, Comunista, de amanhã, pela necessidade e pelo “imperativo categórico" de sua realização.

Tudo isso é atravessado por um desafio de "epistemologia política", de congruência de pontos de vista "epistemológicos" sobre conhecimento e desconhecimento, com posições político-econômico-sociais práticas, com que Marx pretende refutar o ponto de vista liberal e sustentar seu ponto de vista comunista. Com relação a isso, entendo que, não obstante procurar assumir integralmente um ponto de vista prático-relacional, Marx permanece ainda preso a elementos subjetivistas, mentalistas-solipisistas, representacionistas (materialistas burgueses, séc. XVIII, se se quiser), por um subjetivismo magnificado, numa hipertrofia da figura do sujeito, com recurso às categorias do idealismo transcendental alemão. Aqui, entretanto, por razões de espaço, só poderei me ocupar mais diretamente dos primeiros pontos acima listados.

Tomo o pragmatismo, com o qual proponho pôr Marx em diálogo, como uma posição no interior de um conjunto de posições aparentadas, características da filosofia contemporânea. Isto é, como um caso interessante de virada pós-metafísica, de transformação anticartesiana, antissolipsista, não fundacionista, da filosofia. Ou ainda, para não ficar apenas em expressões negativas, como um tipo de virada prática e social da filosofia, conciliada com o tempo, o devir e a contingência no mundo.
Uma das especificidades desse pragmatismo com relação a posições "pós-metafísicas" concorrentes, dos nossos dias, é justamente o seu caráter francamente construtivo, razoável, além de, por suposto, prático-citerior, diesseitig, destranscendentalizante. Nem por isso, entretanto, um ponto de vista desprovido de potencial normativo, crítico, aparecendo como relativista, subjetivista e utilitarista estreito tão somente para mau entendedor. Nessa linha, quando falo em pragmatismo, penso nas suas expressões que, de um modo ou de outro, permitem articular ação e conhecimento a sensibilidade social e comunidade democrática, o leitmotiv do que meu interesse por essa corrente.

Oque me disponho a chamar de pragmatismo de Marx, isto é, do lado pragmatista de seu materialismo prático normativo, são posições expressas, de modo muito condensado, principalmente nas Teses ad Feuerbach (1845), onde ele trata de modificar, justamente por uma acentuação práticoativista, social-comunista, o humanismo-materialismo feuerbachiano - que também guarda afinidades com o pragmatismo. ${ }^{1}$ São posições, as de Marx, já aí comprometidas, porém, com elementos não pragmatistas que eu chamaria de transcendentalizantes (como possivelmente os pontos 4 e 5 acima), além de cartesianos e subjetivistas, que, infelizmente, teriam acabado por acentuar-se e prevalecer na sua obra. Elementos que podem acarretar consequências piores para as práticas nela inspiradas (pelo menos como avaliadas desde esse nosso começo de séc. XXI), mais especificamente para a democracia como a comunidade que queremos. ${ }^{2}$

${ }^{1}$ A filosofia de Feuerbach é um humanismo não apenas em sentido ético (enquanto voltada ao altruísmo), mas também por pretender superar os vícios da filosofia anterior por uma redução ao "humano" - o humano sensível, afetivo, comunitário. O teuto-britânico Ferdinand Schiller (1864-1937), um dos pais-fundadores do pragmatismo, também caracterizou sua filosofia como humanismo, invocando a conhecida máxima protagoriana de que o homem é a medida de todas as coisas, enquanto William James repetia que "o rastro da serpente humana está em todas as coisas”.

${ }^{2}$ As Teses ad Feuerbach aparecem aqui traduzidas por mim do original alemão, Thesen über Feuerbach, publicado em Marx; Engels. Thesen über Feuerbach. In: MARX, Karl; ENGELS, Friedrich. Werke. v.3. Berlim: Dietz Verlag, 1958.O texto original de Marx aparece na p.5 do volume, e a versão modificada por Engels, na p. 533. 
Desse modo, meu tratamento de Marx quer ser aqui, a um só tempo, de interpretação, recuperação e crítica das formulações que trago à discussão, que se constituem num germe filosófico contraditório, além de, por suposto, nas Teses, não desenvolvido. ${ }^{3}$ Formulações das quais Marx teria se afastado, para longe de valiosos insights dos começos do seu não contemplativo materialismo prático-histórico. E digo valiosos porque, de outro lado, não obstante perdidos por Marx e pelo marxismo, poderiam apresentar vantagens com relação a algumas das posições filosóficas que hoje se reivindicam ou são reconhecidas como pragmatistas. Isto é, com relação a formulações do "pragmatismo clássico", mas principalmente com respeito a algumas de suas expressões mais recentes (v. g. Habermas e Rorty). E acredito que o mesmo pode valer para formulações semipragmatistas de autores como Quine ou Wittgenstein, aparentemente enredadas ou limitadas (do meu ponto de vista), seja por certa ideia de ciência natural como paradigma de todo conhecimento, seja por uma "linguistificação" do ponto de vista prático, seja pelas duas coisas. ${ }^{4}$

Trato de me concentrar no exame das Teses em razão de seu caráter sintético, filosoficamente programático, de suas qualidades de germe e cerne, como um conjunto de elementos suscetíveis de interpretação e desenvolvimento. Sobretudo por tais elementos constituírem-se, nessa forma, num poderoso entrelaçamento, numa só concepção, de formulações básicas sobre ação, conhecimento, realidade, subjetividade e normatividade (ou idealidade). É também meu pressuposto que o pragmatismo pode ser tomado, hoje em dia, não apenas como uma determinada corrente ou tradição norte-americana, mas também como um "terreno" (do qual trato justamente de aproximar Marx)

${ }^{3}$ Não obstante isso, é nas Teses que se encontra, para Engels, o embrião de toda a "genial” concepção madura de Marx.

${ }^{4}$ Apesar de sua consideração pela ciência experimentalista, não creio que o pragmatismo, como tradição, deva ser caracterizado como "cientificista” (nem circunscrito como "epistemologia"), ao modo do neopositivismo ou do empirismo lógico, nem, por outro lado, deva ser "tragado" pela virada linguística derivada do campo desses últimos. de interlocução e elaboração filosóficas contemporâneas. Não só porque os próprios "pragmatistas clássicos” (Peirce, James, Schiller, Dewey e Mead) apresentaram-se, de saída, tanto relacionados como consideravelmente diferenciados entre si ("uma casa dividida contra si mesma", dizia Peirce), como também porque assim se apresentam seus mais recentes "filiados" (como Quine, Rorty, Putnam, Wellmer ou Habermas), na interlocução que mantêm uns com os outros e com aquela herança comum. O pragmatismo poderia, então, ser considerado como um terreno para o qual têm convergido - justamente por uma "virada pragmatista" - expressões relevantes da elaboração filosófica contemporânea, de diversa procedência, em confronto e diálogo, como um verdadeiro work in progress, em um campo vivo e aberto. ${ }^{5}$

Para agregar respaldo ao que digo, posso invocar alguns testemunhos respeitáveis, em rápidas pinceladas, cedendo momentaneamente ao que Peirce (1839-1914) chamaria de método de autoridade. Com efeito, Jürgen Habermas, que procede do marxismo e da filosofia clássica alemã, entende que o pragmatismo é, nos nossos dias, uma "ponte transatlântica [entre a Europa e a América] para um vivo intercâmbio intelectual." Segundo ele (que já se considera em posição de corrigir, de um ponto de vista mais pragmatista, o neopragmatismo de Rorty), ${ }^{6}$ é no pragmatismo que desembocam hoje nada menos que os processos conjugados de autocrítica de kantismo e hegelianismo. ${ }^{7}$ O que não deveria soar tão estranho, pois o pragmatismo, Habermas defende (tal como eu), deita raízes também "no idealismo alemão e no próprio Marx," podendo, em certos casos, ser considerado "uma variante democrática do jovem hegelianismo e da

${ }^{5} \mathrm{O}$ pragmatismo de Habermas é assumido abertamente em Verdade e Justificação (2004). Quanto a Albrecht Wellmer (2004). Registrando a mesma virada pragmatista, ver Bernstein (2010). Quanto a Hillary Putnam (1995). Minha alusão ao pragmatismo como "terreno" pode ser ainda interpretada como referência ao seu caráter citerior, destranscendentalizado, isto é, à sua terrenalidade.

6 "O verdadeiro herdeiro do pragmatismo é Habermas" (em comparação com Rorty), conclui Claude Piché (2003, p.25). Sobre isso, ver também Aboulafia; Bookman; Kemp (2002). ${ }^{7}$ Esse é o entendimento de Habermas (1989). O pragmatismo, acredito, é onde bem poderia desaguar igualmente a autocrítica do marxismo - aliás, o próprio Habermas pode ser considerado como uma versão disso. 
filosofia da práxis." Observe-se, com relação a isso, que Peirce, ao tempo em que reconhece suas posteriores convergências com Hegel, admite "ter chegado à filosofia através da porta de Kant," enquanto Dewey e Mead formaram-se inicialmente como hegelianos, e William James em contato direto com o ambiente filosófico da Alemanha e da França do seu tempo. ${ }^{8}$

Do lado da filosofia analítica, Hyllary Putnam, em convergência com Habermas, tem compreendido o pragmatismo como "uma questão em aberto," como "um modo de pensar de duradoura importância," e, finalmente, "uma opção para o pensamento filosófico de hoje." Antes dele, Willard Van Quine, outro analítico que contribuiu para a virada "antidogmática" do empirismo numa direção pragmatista, tratou de acolher o que seriam seus dois melhores achados: 1) que o significado de uma asserção é a disposição de agir de acordo com ela, e 2) que a verdade é, pelo menos em certa medida, criada, e não simplesmente descoberta, pelos homens. Enquanto Putnam, com quem Habermas compartilha um pragmatismo kantianizado, adota expressamente, da tradição pragmatista, entre outras coisas, a rejeição dos dualismos tradicionais da filosofia moderna, em favor da ideia de "interpenetração de fato, teoria, valor e interpretação," que corroeria tanto o "realismo metafísico" como os "pós-modernismos" e "antirrealismos da moda." Por fim, Habermas (que admite sua filiação e de Karl-Otto Apel a Charles Peirce) ainda caracteriza apropriadamente o pragmatismo não só como uma via cosmopolita, contemporânea, de "destranscententalização" e de superação da "filosofia da consciência" e da "razão centrada no sujeito," como também pela "atitude antielitista e democrática, igualitária, [que] penetra o trabalho de todos os pragmatistas". ${ }^{9}$ Com o que já

${ }^{8}$ A influência "continental" certamente não exclui aquela britânica, empirista e utilitarista, socialmente progressista, de Alexander Bain e Stuart Mill. De outro lado, o pragmatismo de Ferdinand Schiller traz a marca de um parentesco nietzschiano, como atesta G. Stack (1982)

${ }^{9}$ Para as afirmações de Habermas - e outras do gênero ver "Filosofia, Pragmatismo e Democracia" (p. 38 ss.), introdução ao meu livro, 2005. Para as de Putnam ver 1995. Sobre o que diz Quine, ver p. ex. De Waal (2005, p. 148-149). A influência de Kant e a convergência com temos aqui elementos para uma noção do que pode ser pragmatismo e para tentar um diálogo crítico com o ponto de vista das Teses a partir dele.

O que dizem afinal as Teses ad Feuerbach sobre a ação? Onde está seu pragmatismo? Bem, numa palavra: aquilo que Marx, como bom pragmatista, faz, nas Teses, é justamente, ao seu modo, introduzir o agir (bem como propósitos e avaliações humanos) "dentro" do conhecer e do "ser”. Para começar, nosso socialista científico, quando constrói seu materialismo práticonormativo (prático-crítico), e trata de falar não escolástica ou metafisicamente, mas praticamente, de realidade e conhecimento, não faz (nas Teses) alusão expressa a "ciência" ou "científico" (não, em todo caso, em sentido "positivista"), nem parece, de início, inclinado a apresentar as coisas como elas seriam "em si mesmas", segundo uma concepção tradicional de objetividade. ${ }^{10}$ Ele insiste, em vez disso, em noções como prática e atividade humana sensível (Praxis e sinnliche Tätigkeit), além de, em consequência, perspectiva ou posição (Standpunkt, ponto de vista) e interpretação práticas, parecendo desinflar, com isso, a noção de teoria. Outro traço que sugere que o materialismo prático das Teses procura fugir do ponto de vista realista-empirista tradicional é também seu recurso reiterado a expressões como "apreender" ou "captar" (fassen), “conceber" (begreifen), "considerar" (betrachen), além de "entender” (verstehen), "interpretar" (interpretieren) e "querer" (will). Pois, embora isso por si só não caracterize uma perspectiva prático-ativa, de centralidade da ação prático-sensível, sublinha um papel ativo para o sujeito que conhece, ainda que seja dele apenas como

Hegel são reconhecidas por Peirce (1983); do mesmo modo que por Robert Brandom, para Kant (Brandom, 2011), e por Robert Stern, para Hegel (Stern, 2011).

10 Marx tem pela ciência apreço semelhante ao do pragmatismo, mas a noção de ciếncia predominante no marxismo tendeu antes para um positivismo dogmático magnificado (com recursos alemães), do que para aquela hipotética, experimentalista, falibilista, de Peirce, Dewey ou James. Em "As Três Espécies de Excelência” (op. cit., p.39), Peirce acentua que "todas as ideias da ciência vêm através da abdução, [que] consiste em estudar os fatos e inventar uma teoria para explicá-los; sua única justificação é que, se for para entender as coisas, deve-se fazer assim." Peirce chega a dizer que a abdução é "a questão do pragmatismo" (p. 57). 
mente ou consciência. Por fim, nas Teses, Marx, tal como vários pragmatistas, parece aproximar fato e valor, realidade e normatividade, descrição e prescrição, ser e dever ser, recusando, quanto a isso, o dualismo rígido de parte da filosofia anterior.

Antes de passarmos diretamente a uma olhada pragmatista às Teses, fique claro que não se trata de medi-las com um metro exterior, previamente fixado. Mesmo porque, está visto, não concebo o pragmatismo (tampouco Marx) como um pensamento uniforme, nem vou enveredar pela a abstração de um núcleo mínimo comum seu, como sua essência. Prefiro, quanto a isso, invocar uma wittgensteiniana semelhança de família, que tentarei justamente estender a Marx: aquela decorrente de fontes e motivos comuns, além de eventuais cruzamentos, o que permite que organizadores de coletâneas e introduções ao pragmatismo saibam, mesmo com alguma variação, quem nelas incluir. ${ }^{11}$ Nesse sentido, o texto sugere uma leitura das Teses desde um ponto de vista pragmatista que adquire contornos na sua própria exposição, num duplo movimento de aproximação e crítica, no qual autores pragmatistas e suas formulações sobre a ação poderão ser invocados de modo ilustrativo, sem que isso signifique que estou operando ecleticamente, por sobreposição.

Mesmo assim, como ajuda adicional ao leitor não especializado, agrego ao que já foi dito o que pode ser considerado um ground zero do pragmatismo, sobre sua ênfase na ação e na prática. Para começar, há a definição de crença, do escocês Alexander Bain, como - bem sucedido hábito de ação, como um juízo "com base no qual se está disposto a agir" - juízo prático, portanto. Pois tal definição aparece como artigo de fé, invocado com igual aprovação por uma variedade de pragmatistas, desde Richard Rorty, num extremo, a Charles Sanders Peirce, no outro; uma definição da qual, ademais, esse último diz ser o pragmatismo “pouco mais do que um corolário." O que nos conduz à chamada máxima do pragmatismo, do pró-

${ }^{11}$ A título de bons exemplos, ver, além da introdução já indicada, de De Waal, também as de Jean-Paul Commetti (1995, 2010); de J. Murphy (1990), e a coletânea de Rosenthal; Hausman; Anderson (1999). prio Peirce, segundo a qual, bem entendida, a concepção adequada de um objeto é a dos seus "efeitos de alcance prático." Pois boa parte do desenvolvimento da tradição pragmatista pode ser compreendida como envolvendo derivações dessa máxima (com diferentes versões já em Peirce), que, como "corolário" da definição de Bain, implica "traduzir" nossas concepções, tanto em termos do comportamento das coisas em relação a nós, como do nosso em relação a elas, dois lados de uma mesma moeda. Por sobre isso, enfim, há ainda não apenas a implicação recíproca de ação, conhecimento e propósitos humanos, como duas outras relacionadas, mais difíceis de esclarecer aqui: a de conhecimento com interpretação e intersubjetividade, e a de ação e conhecimento com normatividade. ${ }^{12}$

Nas Teses, na primeira delas (depois, na quinta), Marx entende que a realidade (Wirklichkeit) deve ser apreendida, não contemplativa ou passivamente, não apenas como "objeto sensível" ou "intuição (Anschauung) sensível," como no empirismo ou "materialismo anterior." Não deve ser captada - a própria realidade, o "mundo sensível" (Sinnlichkeit) tomado como sinônimo - nem mesmo como matéria ou natureza, mas como "atividade humana sensível," como "prática". E isso significa que ela deve ser apreendida também como "subjetiva" (intersubjetiva, preferiríamos hoje). ${ }^{13}$ Ao mesmo tempo objetiva (sensível, material) e subjetiva (humana, histórica), a realidade é, para Marx, a atividade prático-social dos homens, que, de outra parte, constitui seu próprio meio (sensível, material, mas histórico, não natural, não dado, não separado deles): o contexto onde coisas e fenôme-

${ }^{12}$ As caracterizações do pragmatismo têm frequentemente recorrido a sugestivas imagens, mesmo quando a preocupação é defendê-lo como científico. De Waal (2005, p. 175 ss) fala dele como "uma doutrina inquieta," que "nega apaixonadamente que possamos ser meros espectadores," uma filosofia com a "mentalidade pioneira" do Novo Mundo, onde "as velhas regras não mais funcionavam," com a mentalidade de que "nós fazemos nosso mundo," ainda que sempre de modo "realista". Marx, na Ideologia Alemã, declara que os Estados Unidos foram constituí-
dos "pelos indivíduos mais avançados do Velho Mundo" e "pelas formas mais avançadas de interação". Teria ele, nas Teses, se aberto a esse espírito "novo mundo" em proveito de seu ativista materialismo prático?

${ }^{13}$ Onde se dizem práticas, para Marx, dizem-se também as relações que nelas se estabelecem. Ele, entretanto, prefere prática no singular e com maiúscula: a produção econômica. 
nos humanos devem inteiramente caber. Observe-se que, também para o pragmatista John Dewey, a realidade pode ser prática e subjetiva, e que sua crítica da concepção de experiência do empirismo clássico aproxima-o dessas posições de Marx nas Teses. ${ }^{14}$

A IdeologiaAlemã refere-se a essa realidade em devir também como História e Processo Vital, queassocia ainda a noções como "modo de vida" (Lebensweise) e "modo de produção" (Produktionsweise), seu núcleo duro, que dão a ideia de um contexto não só em devir, mas também desdobrado, estruturado, pois, na prática, os homens estabelecem relações - até aqui fixadas - entre si. Essas são noções que, ademais, aproximam-se de uma concepção materialista de cultura, de uma ideia de "espírito objetivo" e de "substância social”, que apontam para a superação do dualismo rígido sujeito-objeto (no plano da realidade como do conhecimento), na sua forma mais classicamente moderna, cartesiana. A primeira seção da Ideologia Alemã chega a definir o real e o homem como uma coisa só, justamente como atividade sensível, duas faces de um só Processo Vital (em última análise a Produção e as relações que ela estabelece) - o que parece dissolver, num grande Curso Real, toda particularidade e empiria.

Esse é o materialismo prático introduzido pelas Teses como superação, informada pelo idealismo transcendental alemão, do empirismo intuicionista-representacionista, cartesianolockeano, robinsonista, que Marx chama de materialismo anterior, este atrelado ao que, para Dewey, é o "ponto de vista do espectador" - de um homem exterior ao mundo, de um mundo exterior ao homem, e de ambos como "fixados" por suas relações. O ponto de vista da intuição sensível é o do isolamento, o da atividade sensível é o das relações. ${ }^{15}$ De modo análogo às Teses, e com preocu-

${ }^{14}$ Ver, de Dewey, o ensaio "Does reality possess practical character?”, republicado em Goodman Ed. (1995). Para a crítica deweyana da concepção de experiência do empirismo, ver p. ex. Dewey (1917). Ainda sobre a noção de experiência em Dewey o no pragmatismo americano, ver Jay (2004).

${ }^{15}$ Marx, em outros textos, usa o termo "robinsonada" (em alusão ao personagem Robinson Crusoé), para denunciar a ilusão da economia política e da teoria social burguesas dos sécs. XVIII e XIX, de conceber os indivíduos (no interior da economia e da sociedade) como realidades "independentes" e "anteriores" à sociedade e à história (vide pações semelhantes, de trazer a filosofia para o mundo sem abrir mão do ideal, William James entende seu pragmatismo como uma terceira via (ou via mediana) entre empirismo e racionalismo, entre realismo e idealismo. Tal como Marx, James quer nos oferecer um ponto de vista que tenha a marca do espírito realista prático da Modernidade, e que, ao mesmo tempo, não exclua, antes sustente, a dimensão do ideal. E ele faz isso invocando, contra a alternativa de sublimação racionalista metafísica do mundo (como no leibniziano "melhor dos mundos possíveis"), a "rua" (o mundo real, vivido, contraditório, da finitude humana) e, principalmente, a crueza da questão social, na forma da fome, do desemprego e do drama da vida dos trabalhadores de Cleveland. ${ }^{16}$

O fato é que, envolvido, ao mesmo tempo, com os fatos e com o ideal, por sua noção de prática, o novo materialismo de Marx permite entender o contexto dos homens como em devir e como história (das relações entre eles), com uma referência forte de futuro, o que faria dele algo como um pragmatismo histórico. Isso, entretanto, em termos, pois a história de Marx (veja-se novamente A Ideologia Alemã) é, antes, um processo presidido por uma certa necessidade que também circunscreve o futuro, e onde, não obstante a centralidade da prática, a admissão da contingência deve ser superada pelo reconhecimento consciente de uma necessidade racional-dialética prevalente, ao tempo em que quer ser a moldura que dá a cada evento particular seu significado propriamente histórico. Por isso, na consagrada concepção materialista da história, a prática, a ação, a atividade humana sensível, orientada para o futuro, não encontra propriamente um campo de possibilidades abertas, nem parece realizar uma criação digna do nome, como posições pragmatistas tradicionalmente gostariam.

Em compensação, Marx consegue, com ela, prover os juízos de valor com uma força incompa-

Teses Seis e Sete). Aqui trato de estender o uso crítico dessa metáfora ao individualismo epistemológico (possivelmente próprio também a Marx), como se verá melhor mais adiante.

${ }^{16}$ Veja-se a primeira conferência de James The present dilemma in philosophy (1995). 
rável, pela definição e garantia de um Telos, Ideal ou Bem (absoluto, porque incontrastável), a Sociedade Humana ou Humanidade Social, que deve dar sentido último às ações dos homens. Coisa também sustentada, de outra forma, em versão mais fraca, apenas como esperança razoável, no pragmatismo de Peirce. A moldura histórica (de sucessão de modos de produção) de Marx pode ser flexibilizada para além das poucas etapas e do determinismo rígido em que Stalin a encaixou, mas não ao ponto de perder seu sentido transcendental de permitir ajuizar valorativamente, com força de necessidade, de modo geral binariamente, as posições e ocorrências no seu interior, em especial as do presente, que é o que mais interessa a Marx. ${ }^{17}$ Em qualquer caso, o que cabe assinalar é principalmente que marxismo e pragmatismo são modos de pensar que tratam de introduzir, no pensamento filosófico, não só um senso prático-ativo, mas igualmente um senso prático-normativo. Apenas, no caso de Marx, não é simplesmente a "História" que tem proeminência nesse papel, mas, em associação com ela, nas Teses, a ideia de uma "essência” do homem que teria seu lugar nas relações sociais em desenvolvimento, aquelas em que justamente a atividade prática (produtiva) os introduz. Coisa que Marx retorna no Capital, creio eu, de modo "cientificamente" reelaborado, com resultados "normativo-transcendentalizados" ainda mais fortes - mas isso é outra história.

A atividade sensível, prática, social, dos homens, subjetiva, mas também objetiva, vai ser entendida por Marx como Produção (sua "Prática das práticas”), como trabalho humano sobre a natureza; ou seja, alegam seus críticos, como ação instrumental apenas, e não devidamente aprecia-

${ }^{17}$ Com relação à história de Marx, ver Souza (2006b). Quanto a Peirce, ele sustenta a ideia de uma comunidade ilimitada de investigação como verdadeiro sujeito do conhecimento, orientada pelo ideal imanente de um consenso final; uma comunidade real, onde cada um age como membro de uma comunidade ideal, ou como membro de sua comunidade idealizada. Entretanto, aqui me refiro a outra coisa: à noção peirceana de um Telos último, absoluto, de um Ideal admirável, "que reside no próprio processo evolutivo,” como “amor evolucionário,” e que deve ser referência ética para todo ato voluntário (op. cit., p. 5 a 38 passim; também Evolutionary Love, em The Monist, v. 3, n. 1, p. 188). Para Dewey, "é a democracia o Ideal supremo, ético, da humanidade“ (apud Anderrson 1993, p.383). da na especificidade de sua dimensão humana de interação dos homens entre si enquanto sujeitos de intersubjetividade. Creio que há, no entanto, um problema mais relevante a destacar, desde um ponto de vista pragmatista, na compreensão marxiana da realidade como prática ou atividade sensível, nas Teses. O problema é que, depois de definir o real como objetivo-subjetivo, enquanto atividade humana sensível, prática, e de parecer flexibilizar, por essa via, oposições binárias e dualismos estritos da velha filosofia, a Tese Primei$r a$ faz uma acentuada distinção de valor, e começa a construir uma oposição e uma hierarquia, entre dois tipos de atividade prática. De um lado, uma atividade superior, legítima, universal; de outro, uma atividade não "genuinamente humana", que traz a marca da separação e da particularidade - ao que parece, a atividade da maioria dos homens.

Essa segunda é a atividade deles como parte da sociedade civil burguesa (bürgerlich Gesellschaft), em sua dispersão e mútua oposição, determinadas, em última análise, pela divisão do trabalho (ou da prática), tomada como um mal e uma perversão das coisas. É essa segunda prática, que Marx vai considerar como falsa e corrompida, que as Teses chamam de "suja" e "judaica" (egoísta, no feuerbachês da Essência do Cristianismo), além de "fixada", "fenomênica", "forma aparente" (Erscheinungsform) - em oposição à outra, que é "essencial" e "genuinamente humana" (echt menschliche). ${ }^{18}$

Em última análise, é à esfera da prática ordinária que pertence, Marx nos diz mais adiante, nas Teses Nove e Dez, o materialismo intuicionistasensível, supostamente não-prático, próprio da perspectiva (Standpunkt) da Sociedade Civil. As Teses ad Feuerbach se dispõem a caracterizar, tanto essa concepção materialista-empirista como aquela atividade prática estreita, que também criticam, como do nível da aparência, da superfície; enquanto a outra, por oposição, seria de fundo e essencial, e, de certo modo, teórica e crítica. Isso no sen-

18 Quando Marx ou Feuerbach referem-se a "humano" (menschlich), o adjetivo, em geral, tem sentido valorativo, de humano verdadeiro, com alcance ético, oposto a "egoísta”, etc. O termo alemão menschlich pode ser traduzido também por humanitário. 
tido de conforme à razão, iluminada e justificada pela "teoria", análoga, assim, à atividade intelectual (idealizada, naturalmente): desinteressada e universal. Marx teria aqui a oportunidade de associar a suposta universalidade e racionalidade dessa boa prática à ampla interação - política - entre os homens, e à autoridade de uma intersubjetividade agonística, no âmbito da esfera pública, mais do que à sua teoria "transcendental". As Teses, porém, têm suas razões para evitar esse caminho, o que, para Marx, representaria justamente um perder-se no nível da superfície e das aparências do mundo sensível (ao fim e ao cabo, o mundo das trocas mercantis), que é o nível do fetichismo, e deixar - enquanto na busca de um ponto de vista mais cabalmente prático - o verdadeiramente crítico e revolucionário de lado.

De qualquer modo, as Teses aqui parecem isolar e inferiorizar, em bloco, como alienada, uma esfera que parece incluir a Alltagsleben, a prática ordinária do comum dos homens, orientada para a realização de fins particulares, privados, justamente a que mais se poderia conceber como mundana, citerior, diesseitige. Já a outra prática, superior, melhor denominada pela palavra grega e alemã Praxis (com maiúscula, naturalmente), poderia ser entendida como o trabalho dos homens enquanto socialmente concebido, enquanto atividade cooperativa e universalizada, como seria sua suposta natureza, de fundo. Mas é, na verdade, em primeiro lugar, a denominada atividade revolucionária, aquela generosa, idealista, iluminada teoricamente, sancionada filosoficamente. ${ }^{19} \mathrm{Uma}$ atividade que, como me parece ser a ideia de Marx, de algum modo "mimetiza" a atividade produtiva, cooperativa, dos homens, enquanto socialmente orientada, uma atividade que "replica" o caráter essencialmente - embora, nas condições da divisão (antagonista) do trabalho, oculta e alienada-

${ }^{19}$ Sob esse aspecto, Feuerbach é menos essencialista e mais pragmatista do que Marx. Para o primeiro, a prática humana positiva é, sobretudo, afetiva, não depende da teoria, e encontra base nos comportamentos afetivos e solidários dos homens no interior da própria sociedade existente. Para ele, deixada a religião para trás, a fraterna essência humana não pode ser de novo separada dos homens e posta para muito longe deles e de sua existência presente. Sobre isso, ver Souza (2006a). mente - social do trabalho. Algo que só se exibirá e realizará segundo sua verdade e às claras, num outro contexto, o da futura produção social comunista, uma vez abolidas a divisão do trabalho e a particularista sociedade civil burguesa.

Marx, por outro lado, não parece considerar que, enquanto a atividade prática "menor" é orientada pelo interesse particular, a "maior", como prático-crítica e revolucionária, não estaria orientada apenas pela e para a transformação e autotransformação virtuosas dos homens, no sentido da universalidade, mas também para a tomada do poder, sendo ainda passível de converterse, adiante, em atividade burocrática de Estado, separada e acima da sociedade, como portadora ideológica do suposto interesse humano - ou proletário-geral.

Por essas e outras, uma posição mais efetivamente prática (ou pragmatista) talvez não devesse desqualificar as práticas do comum dos homens, bem como as concepções que lhes correspondam, em nome de outra prática inteiramente superior e distinta, estabelecida pela teoria ou pela ciência e prescrita pela própria realidade no seu nível mais profundo. Nem deveria enfrentar, para isso, o risco de assumir, sob nova forma, o dualismo essência e aparência da filosofia tradicional, contemplativa, em que Marx vai cada vez mais se enredar, até sua culminância no Das Kapital. Como entendo, $O$ Capital se empenha em consolidar a separação das Teses entre fundo e superfície, essência e aparência, não recuando, para isso, em propor a figura de uma aparência real, a do nível da circulação, onde os homens comuns enganosamente "imaginam-se" livres. É aí “o Paraíso dos direitos do homem, onde unicamente imperam a Liberdade, a Igualdade, a Propriedade e Bentham," diz Marx ironicamente..$^{20}$ De todo modo, as Teses partem de uma concepção de realidade como atividade sensível, como concepção que corresponde às necessidades de transformação radical da sociedade e a potencialidades postas pela dinâmica dessa realidade nova, a Modernidade, como lida "teoricamen-

${ }^{20}$ Sobre isso, ver Souza (2004b). 
te" (dialético-hegelianamente) por Marx. E é o instrumental teórico a partir daí desenvolvido, seu materialismo prático-normativo (Marx, já dissemos, oferece "comunismo" como sinônimo, na Ideologia Alemã), um materialismo histórico-dialético, que vai, aos poucos, nos parecer cada vez menos simplesmente materialista e prático, e cada vez mais essencial-transcendentalizante.

Logo adiante, na Tese Terceira, Marx vai, entretanto, investir ele próprio contra uma divisão semelhante àquela que faz entre práticas, acreditando poder prevenir sua consumação justamente pelas virtudes de sua noção de atividade revolucionária prático-crítica (introduzindo, aqui, sua tematização epistemológico-política). Marx fala, aí, do problema trazido à realidade e à prática por uma forma equivocada de pensamento (e não o contrário, como pretende fazer a maior parte do tempo). Numa crítica à permanência de vícios da filosofia anterior, mesmo numa "doutrina materialista" voltada para a transformação da realidade e dos homens, a Tese Três entende que os reformadores materialistas, que pensam "transformar as circunstâncias" para "transformar" e "educar" os homens, acabam por colocar-se acima deles, tomados, então, como simples objetos ou produtos. Quando deveriam atentar para o fato de que, se os homens são transformados pelo meio, "são eles próprios que o transformam," e que os educadores precisam ser igualmente transformados.

Embora Marx aqui pareça aceitar uma problemática divisão, paternalista, de papéis (educadores, de um lado, e educandos, de outro, mesmo que para concluir com a famosa tirada de que "o educador deve ser educado," socializado), ele acredita poder resolver o problema dessa hierarquização, fazendo coincidir três dimensões da atividade prática sensível: 1) a prática de "transformação das circunstâncias" (entenda-se, a intervenção dos “reformadores”), e 2) “a atividade humana" (a atividade espontânea dos homens, ou, pelo menos, dos trabalhadores), com 3) o movimento de "autotransformação" da realidade (que, para Marx, já tem objetivamente o sentido de constituir os homens como plenamente sociais) - no interior do qual, como atividade sensível, afinal de contas tudo se dá. Marx imagina encontrar essa feliz e absoluta coincidência (Zusammenfallen) justamente num tipo especial de atividade humana, na superior "prática revolucionária crítica" como "racionalmente entendida" - guiada aparentemente por sua própria Teoria.

A Terceira Tese refere-se à "doutrina materialista" de reformadores sociais do tempo de Marx, que têm, na cabeça, a Ideia de uma sociedade humanizada e de um homem social ou socializado, e tratam de agir para realizá-la - pela "educação" e pela "transformação das circunstâncias" dos homens. Marx crê que, nesse esforço, aquela doutrina, ainda que materialista e, de algum modo, prática, acaba por "separar a sociedade em duas partes": de um lado, os que sabem, os agentes, formadores (como o Rei Filósofo de Platão, o Colégio dos Sábios de Saint-Simon, ou outro tipo de Clero ou Sacerdócio qualquer), e, de outro lado, os homens comuns, o povo, os leigos, envolvidos nas atividades e negócios humanos e na materialidade prático-empírica do mundo. Uma doutrina assim acabaria mesmo por colocar uma das partes (os "transformadores da sociedade") acima da outra, mais exatamente "acima da sociedade" toda (!), constituindo-a como uma espécie de nova e científica Teocracia, como governo dos detentores do acesso à Teoria e ao Ideal. Caso em que ocorreria coisa comparável ao que Marx condena como mais próprio da condição (ruim) dos homens no Capitalismo: uma instância (no caso, possivelmente, o Estado) faz-se grande Sujeito, frente aos homens, reduzidos assim a não sujeitos, objetos ou coisas passivas. É notável que Marx denuncie, nessa Tese Terceira, uma divisão e hierarquização da sociedade em dois estamentos, que não aquela decorrente da propriedade privada e da exploração econômica, mas de um saber como propriedade privada, que não só não teria a ver com a dominação econômica capitalista, mas decorreria de um esforço por sua eliminação.

Se, na Terceira Tese, fica visto que não é uma sociedade assim hierarquizada que Marx gostaria de promover (um despotismo esclarecido ou 
uma “estatização” da iniciativa social, aos quais o pragmatismo é francamente avesso), não fica claro, porém, se seu novo e corrigido materialismo prático normativo, comunista, poderia afastar seu ideal social inteiramente da vicissitude que critica. Pois parece que Marx logo encontrará para sua teoria uma posição muito acima das - e até oposta às - percepções dos homens comuns; uma visão superior das coisas, que, por definição, lhes escaparia. Frente a uma verdade tão acima do comum dos homens e de suas práticas, eles ficariam em condição semelhante à que são relegados por Platão, na Alegoria da Caverna: considerados pelo "homem teórico" como ignorantes, alienados da verdadeira realidade e de si mesmos, que tomam por verdade a simples aparência (dos sentidos), a qual é o inverso do verdadeiro real, inteligível. Marx, porém, de seu lado, tem suas razões para alegar que não incorre nesse erro, justamente por ter em vista a ambicionada coincidência da intervenção transformadora (sobre as “circunstâncias”) e da atividade espontânea (da massa dos homens), com a dinâmica objetiva (como autotransformação) do próprio Real (teoricamente apreendida e explicada), no que ele denomina de "prática revolucionária" (como verdadeiro fazer da História, como por Marx concebida).

As Teses supõem, assim, que seu materialismo prático-normativo dá conta, como teoria, do que seria o movimento (dotado objetivamente de Sentido) da própria Realidade, na direção (positiva) que Marx decifraria “cientificamente”, e supõe que a prática nele inspirada apenas trata de objetivamente coincidir com tal movimento. Com efeito, Marx, no início do capítulo II do Manifesto Comunista, declara que "as proposições teóricas dos comunistas não repousam em ideias descobertos por este ou aquele melhorador do mundo; são apenas expressões gerais do movimento histórico diante dos nossos olhos.” É, entretanto, significativo que Engels, quando retocou as Teses décadas depois, tenha, na Tese Três, suprimido a "espontânea" Autotransformação, que integrava o tripé proposto por Marx, e trocado a expressão, mais nobre, “revolutionäre Praxis,” pela aparentemente mais modesta umwälzende (reviradora, subversora) Praxis. ${ }^{21}$

Enfim, depois de uma tomada de posição com relação à "natureza” da realidade (prática, mas desdobrada em duas), e da nossa relação com ela (nosso autor fala de práticas e posições, não de uma realidade "em si”), Marx se volta, nas Teses (dois e cinco), para a questão da verdade e do conhecimento, e, para tanto, já preparou o terreno na Tese Um. Se a realidade é atividade humana sensível ${ }^{22}$ e nós também o somos, então estamos, enquanto conhecedores (mas não só), nela “já sempre” envolvidos, pela ação como pelos sentidos ${ }^{23}$, pelo pensamento (pois seria tolice imaginar uma prática sem pensamento, do mesmo modo que um pensamento dissociado dela) como pela linguagem..$^{24}$ Não somos exteriores à realidade, nem ela exterior a nós, nem nós uns aos outros, como indivíduos abstratos, sem relações, como mentes individuais desencarnadas, especulares. De outro lado, a realidade humana sensível, como subjetiva (ou intersubjetiva), já sempre está impregnada de atividade humana; logo, de pensamento, conhecimento, crenças e propósitos humanos. Feuerbach, diz Marx nas Teses (tese cinco),

${ }^{21}$ A social democracia alemã, já era então um movimento político desenvolvido, que não sabia como lidar com antihierárquicos “espontaneísmos” e "anarquismos” no interior do movimento operário e da sociedade. Quanto a nós, teríamos desejado que Marx simplesmente entendesse que uma transformação da sociedade seria verdadeira Autotransformação por via de uma democracia mais efetiva e radical, e que unicamente assim ela seria, como ele sugere, "racionalmente [rationell] compreendida."

${ }^{22}$ A ênfase de Marx no sensível parece encontrar eco no texto anticartesiano de Peirce (1975), onde Peirce insiste, não somente em consequências práticas (practical bearings), como também em "resultado sensível“, "efeitos sensíveis", "características sensíveis". Mais tarde, Peirce agregará que se trata de considerar as consequências práticas "resultantes da verdade da concepção" (pref. às Conferências, p.7). É essa referência sensível, práticomaterial, que acredito foi desconsiderada no desenvolvimento "linguístico" do pragmatismo.

${ }^{23}$ Esse envolvimento, concreto, dos homens com o mundo é também necessariamente estético - tanto quanto operativo, cognitivo etc. - como entendem, por exemplo, Dewey e Nietzsche. Mas Marx não dá, nas Teses qualquer atenção a esse estético, como tampouco ao criativo. E o pragmatismo de Habermas decididamente tampouco o faz.

${ }^{24}$ A inseparável imbricação do pensamento com a realidade humana ou contexto enquanto atividade social sensível dá-se também na linguagem e pela linguagem para Marx, na Ideologia Alemã, o pensamento real, prático, "aquele que existe também para os outros homens." Cf. Marx; Engels (1958). 
“descontente com o pensamento abstrato," quer afirmar a realidade do sensível como irredutível ao pensamento. Por isso "apela à [verdade da] intuição [sensível]”: porque "quer objetos sensíveis, realmente distintos dos objetos pensados", ou seja, quer objetos não reduzidos a representações, a imagens em nossas mentes. Do ponto de vista de Marx, no entanto, como nos parece, Feuerbach não deixará completamente para trás o mentalismorepresentacionismo subjetivo-logo, tampouco, seu veneno idealista-robinsonista, herdado pelo "materialismo anterior" -, se não abandonar inteiramente, do mesmo modo, o sensacionismo-intuicionismo e se não passar a apreender o real como prática humano-sensível, incluindo aí as relações que nela se estabelecem (das quais o próprio sujeito conhecedor participa).

Disso tudo decorreria a posição de Marx a respeito de conhecimento e verdade (tese dois), posição que ele caracteriza de "anti-escolástica" (não intelectual-verbalista, não teoricista, suponho), segundo a qual a pergunta pela verdade ou não verdade objetiva do pensamento humano é respondível apenas "na prática". ${ }^{25}$ Pois "verdade" (Marx poderia dizer "verdade objetivo-subjetiva”) é apenas um nome para "efetividade" (Wirklichkeit, realidade efetiva), "poder" (Macht) e "terrenalidade" (Diesseitigkeit, citerioridade) do pensamento " $n a$ prática" (prática sensível-social, podemos entender). E essa seria a compreensão materialista prática de verdade e objetividade do pensamento, uma compreensão anticética e realista, ${ }^{26}$ ao mesmo tempo não comprometida por problemas de correspondentismo e representacionismo, por perplexidades mentalistas céticas sobre o acesso ou

${ }^{25}$ No pragmatismo, frequentemente se prefere a noção de crença para o que aqui se chama de pensamento. Crença é o que temos boas razões, razões aceitáveis, para sustentar; aquilo segundo o que estamos dispostos a agir e efetivamente agimos. É o melhor conhecimento que temos, embora, por princípio, falível e provisório.

${ }^{26} \mathrm{O}$ campo pragmatista, sustentando uma noção práticosocial de conhecimento (em distinção ao "empirismo dogmático" e ao "realismo metafísico"), deve enfrentar o desafio de estabelecer outro realismo. Creio que a noção de realidade como atividade sensível oferece uma pista para isso - para fora do velho realismo dogmático tanto quanto do relativismo do recente contextualismo linguístico. Isso faz parte do que estaremos tratando de ver com o projeto ora proposto. não a uma realidade "em si" - a supostos dados imediatos ou certezas autoevidentes. ${ }^{27}$ Pois podemos entender que, para Marx e seu materialista ativo, não se trata simplesmente de tomar a prática como critério da verdade, mas de dar à verdade um sentido prático, recuperando-a para dentro do horizonte da atividade humana sensível (ou contexto prático-sensível) e de lhe dar uma tradução sensível, nas práticas e condutas que sustenta. ${ }^{28}$ Desse modo, trata-se de associar o valor de verdade de um pensamento ao seu poder para realizar alguma coisa, no trato ativo, prático-sensível, com o mundo-comoferramenta, em vez de retrato mental da realidade. "É na prática que o ser humano deve demonstrar a verdade de seu pensamento."

Na Ideologia Alemã, Marx refere-se aos desvios não práticos, contemplativos (anschauungen), não apenas do materialismo anterior, mas também do "platonismo" da filosofia tradicional em geral, pondo sua origem na divisão de classes das sociedades hierárquicas, pré-modernas, de modo semelhante ao que fará Dewey no Reconstrução em Filosofia.$^{29}$ Marx vê a separação social entre trabalho intelectual, da aristocracia dominante, e trabalho prático-mundano, dos homens comuns, por trás das concepções filosóficas do conhecimento verdadeiro como inteligível puro, como acesso a essências suprassensíveis, pelo "homem teórico” (como filósofo, padre ou sacerdote). E, de outro lado (do lado “de baixo”), relegado à superfície e ao inessencial, o "falso conhecimento" dos homens comuns, o "impuro” conhecimento prático-sensível, envolvido nos negócios humanos e na materialidade do mundo.

${ }^{27}$ Correspondentismo aqui se refere à tradicional definição de verdade como correspondência entre o pensamento e a coisa, ou entre os juízos (pedacinhos de linguagem) e os fatos (pedacinhos de realidade) a que se referem, uma noção (que o pragmatismo procura evitar) que se bate com a dificuldade de "igualar" duas coisas tão heterogêneas, como também com o problema de oferecer a posição (exterior) desde a qual ela (a correspondência) pudesse ser verificada.

${ }^{28}$ Marx recorre apenas uma vez, nas Teses, ao termo conduta (Verhalten, comportamento), quando se refere, na primeira tese, ao comportamento teórico que Feuerbach aprova, em contraposição à prática, tomada como subjetivista, egoísta. O critério da prática, e da "tradução" em comportamento, parece ter, nas Teses como no pragmatismo, também um caráter "terapêutico" para o pensamento, na eliminação de dilemas mentalistas e de nebulosos desvios especulativos.

${ }^{29}$ Ver cap. I em Dewey (1959). 
Por essa divisão é que o pensamento (na filosofia) teria podido imaginar-se "emancipado" do mundo, separado da atividade prática dos homens, teria "passado à formulação da Teoria pura e da Filosofia pura" e à construção sobre ideias de permanência e essência, sobre noções transcendentais de verdade e razão. Dewey critica de maneira semelhante o "paradigma grego" de conhecimento não experimentalista, não prático, condenando também o modelo da filosofia tradicional, de sistema, e sua noção contemplativa de razão. Tudo isso correspondendo, para Dewey, à “situação pré-democrática do mundo,”, aquela de sociedades estáticas hierárquicas, como também, nas sociedades modernas, à remanescente cultura intelectualista, sem sentido experimental-transformador.

A Tese Dois, junto com a Onze, final, que conclama a "transformaro mundo", constitui aquilo que aparece, para qualquer leitura superficial, como a expressão mais pragmatista de Marx, como Bertrand Russell a invocou no debate com o experimentalismo e instrumentalismo de Dewey (para quem o conhecimento é, sobretudo, uma prática e uma ferramenta). ${ }^{30}$ Ela, de fato, lembra, ao relacionar verdade com poder e efetividade de um pensamento, as opiniões mais comuns acerca da noção de verdade no campo do pragmatismo, em geral aquela atribuída a William James. ${ }^{31}$ Mas também aquela do próprio Dewey: verdade e conhecimento como o que resolve problemas, o que funciona na prática, o que dá certo, com que se obtém sucesso. Verdade como aquilo que é útil ou expediente, ou mesmo, no extremo, como a qualidade de uma crença (no caso das mais gerais, não verificáveis) de ter consequências subjetivamente boas - agradáveis, confortadoras ou interessantes

${ }^{30}$ Acho filosoficamente mais sofisticado associar as Teses de Marx ao anticartesianismo do pragmatismo, que muitos não se dão ao trabalho de conhecer. Em todo caso, Dewey, um crítico contumaz da noção abstrata de experiência, do empirismo passivo-intuicionista, presta-se de pronto, por seu pragmatismo socialmente engajado, de esquerda, a uma aproximação a Marx - bem feita por Georges Novack (1975).

${ }^{31}$ Ver James (1979). A respeito do que ele diz da verdade, difundiu-se até hoje mais preconceito do que conhecimento. Para uma apreciação justa da posição de James, ver, de Putnam, The permanece of William James, no livro já referido.
- de tipo existencial, para quem as sustenta. ${ }^{32}$

Do lado do marxismo tradicional, o mais comum é retrucar que, enquanto, para o pragmatismo, o que funciona é verdadeiro, para Marx, aquilo que é objetivamente verdadeiro funciona (além de que, claro, não se deveria deixar de perguntar para quem funciona). O que, entretanto, deixaria ao materialista prático a tarefa de dar conta prático-materialistamente da distinção entre as duas coisas, de estabelecer a verdade objetiva em isolamento da prática - isto é, de fora do horizonte do trato com o mundo e com os homens. De qualquer maneira, o fato é que ambos, pragmatismo e materialismo prático-ativo, falam de pensamentos e ideias não como simples asserções desligadas da vida, mas como crenças que nos orientam na prática (e que podem ser verificadas por outros ou justificadas para eles) - como juízos práticos ou guias para a ação. E falam, por isso, de dúvidas e divergências quanto à verdade e ao significado de um pensamento como decidíveis socialmente, no debate (Streit), além de definíveis apenas na prática e postas na prática e pela prática. ${ }^{33}$ A questão é ver quão consequente cada um deles, pragmatismo e materialismo prático, consegue ser por essa via, mas não teremos para isso, aqui, uma resposta conclusiva.

Recebido para publicação em 16 de outubro de 2012 Aceito em 04 de novembro de 2012

\footnotetext{
${ }^{32}$ De outro lado, é também característica do pragmatismo a noção de verdade como afirmabilidade garantida ou justificada, com base nas evidências disponíveis e aceitas, para a audiência concernida. Ou como a afirmação para a qual necessariamente convergem, "lá na frente", os integrantes de uma comunidade de investigação.

${ }^{33}$ A noção pragmatista de crença tem um sentido em parte próximo da noção prático-materialista de ideologia, ambas tomando o pensamento por seu conteúdo prático, social, orientador da ação e interessado. Mas, sintomaticamente, para ideologia acabou prevalecendo a implicação de conhecimento distorcido ou falso, em oposição à verdade honesta da ciência. A propósito da identificação marxiana de verdade com força e efetividade práticas, parece-me que, uma vez estabelecida a realidade como atividade humana sensível, o conhecimento tenderia mesmo a adquirir um sentido predominante de know-how (de competência para lidar com) - não apenas simplesmente de um pensamento verificado na prática.
} 


\section{REFERÊNCIAS}

ABOULAFIA, Michael; BOOKMAN, Myra; KEMP, Catherine (Ed.) Habermas and pragmatism. Londres: Routledge, 2002.

ANDERRSON, Douglas. The Journal of the American Academy of Religion, v.61, n.2, p.383, 1993.

BERNSTEIN, Richard. The pragmatic turn. Cambridge: Polity Press, 2010.

BRANDOM, Robert. Perspectives on pragmatism. Cambridge: Harvard University Press, 2011.

COMMETI, Jean-Pierre. Filosofia sem privilégios. Porto,Pt: Edições Asa, 1995.

Qu'est-ce que le pragmatism? Paris: Gallimard, 2010.

DE WAAL, Cornelis. On pragmatism. Belmont: Wadsworth, 2005.

DEWEY, John. A common faith. New Haven: Yale University Press, 1934

Does reality possess practical character? In: GOODMAN, R. (Ed.) Pragmatism: a contemporary reader. New York: Routledge, 1995.

Reconstrução em filosofia. São Paulo: Companhia Editora Nacional, 1959

The need for a recovery of philosophy. In: DEWEY, $\overline{\text { John }}$ et al. Creative intelligence: essays in the pragmatic attitude. New York: Holt, 1917.

EGGINTON, William; SANDBOTHE, Mike (Ed.) The pragmatic turn in philosophy. Albany: State University of New York Press, 2004

GOODMAN, Russell B. (Ed.) Pragmatism: a contemporary reader. New York: Routledge, 1995.

HABERMAS. Jürgen. A filosofia como guardador de lugar e como intérprete. In: Consciência moral e agir comunicativo. Rio de Janeiro: Tempo Brasileiro, 1989. 2004

Verdade e justificação. São Paulo: Edições Loyola,

HOOK, Sidney. Towards the understanding of Karl Marx. New York: John Day Company, 1933.

HOOPES, James. Community denied: the wrong turn of pragmatic liberalism. Ithaca: Cornell University Press, 1998.

JAMES, William. The present dilemma in philosophy. In: Pragmatism. New York: Dover, 1995.

Concepção da verdade no pragmatismo. In: JAMES William. Em Pragmatismo (VI - I Conferência). São Paulo: Abril Cultural, 1979. (Coleção os pensadores).

JAY, Martin. Songs of experience. Berkeley: University of California Press, 2004.

MARX, Karl; ENGELS, Friedrich. Die Deutsche Ideologie. MEW. v.3. Berlim, Dietz Verlag, 1958.

1972 . La sainte famille. Paris: Éditions Sociales,

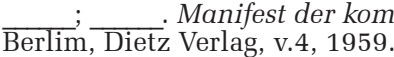

O Capital . São Paulo: Abril Cultural, 1983. v.1

Thesen über Feuerbach. In: MARX, Karl;

ENGELS, Friedrich. Werke. v.3. Berlim: Dietz Verlag, 1958.

Zur Kritik der hegelschen Rechstsphilosophie.

Einleitung. In: LÖWITH, K. Die hegelsche Linke. Stuttgart:

Fromman Verlag, 1962.
MURPHY, John. Pragmatism from Peirce to Davidson. San Francisco: Westview Press, 1990.

NOVACK, George. Pragmatism versus Marxism. New York: Pathfinder, 1975.

PEIRCE, Charles S. Conferências sobre Pragmatismo. (pref., p., conf.I, p.15) In: PEIRCE \& FREGE. São Paulo: Ábril Cultural, 1983. (Coleção os pensadores).

As três espécies de excelência. In: PEIRCE \& FREGE. São Paulo: Abril Cultural, 1983. (Coleção os pensadores)

Evolutionary love. The Monist, [S.1.], v.3, n.1 892. Disponível em: revistas.pucsp.br/ index.php/ cognitiofilosofia/article/download/.../922.

Como tornar claras nossas ideias. In: MOTA; HEGENBERG (Org.) Semiótica e filosofia. São Paulo: Cultrix, 1975

PICHÉ, Claude. A passagem do conceito epistêmico ao conceito pragmatista de verdade em Habermas. In: ARAÚJO, L. (Org.) A filosofia prática e a modernidade. Rio de Janeiro: UERJ, 2003.

PUTNAM, Hillary. Pragmatism, an open question. Cambridge: Blackwell, 1995.

RORTY, Richard. Philosophy and social Hope. Londres Penguin Books, 1999.

ROSENTHAL, S.B.; HAUSMAN, C.R.; ANDERSON, R. (Ed.) Classical American pragmatism: its contemporary vitality. Chicago: University of Illinois Press, 1999.

SOUZA. José Crisóstomo de. Teses de Marx: para uma crítica ao (não-)pragmatismo de Marx. Cognitio, São Paulo, PUCSP, v. 13, p.115-144, 2012.

A virada prático-histórica da filosofia: hegelianismo, pragmatismo, pluralismo, democracia. Salvador: EDUFBA, 2012. v.1. 154p.

Feuerbach, crítica da religião, crítica da modernidade. In: CHAGAS, Eduardo; REDYSON, Deyve, PAULA, Marcio G. de (Org.) Homem e natureza em Ludwig Feuerbach. Fortaleza: Edições UFC, 2009. p.241-270.

Marx and Feuerbachian essence. In: MOGGACH, D. (Ed.) The new Hegelians: politics and philosophy in the Hegelian School. Cambridge: Cambridge University Press, 2006a.

A filosofia marxiana da história como Selbsterzeugung do homem. In: SANTOS, A. C. História e ação. São Cristóvão,Se: Ed. UFS, 2006b.

. Filosofia, pragmatismo e democracia (introdução). In: (Org.) Filosofia, racionalidade, democracia. Sẫo Paulo: Unesp, 2005.

Karl Marx como John Dewey: o marxismo pragmatista de Sidney Hook. Veritas, Porto Alegre, PUCRS, v.49, n.1, 2004a.

A teoria marxiano-althusseriana do desconhecimento no Capital. Ideação, Feira de Santana,Ba; UEFS, v.1, 2004b.

STACK, George. Nietzsche's influence on pragmatic humanism. Journal for the History of Philosophy, Oxford, Routledge,v.20, n.4, out., 1982.

STERN, Robert. Hegelian metaphysics. Oxford: Oxford University Press, 2011.

WELLMER, Albrecht. The debate about truth: pragmatism without regulative ideas. In: EGGINTON, Willian; SANDBOTHE, Mike (Ed.) The pragmatic turn in philosophy. Albany: State University of New York Press, 2004 


\section{ON PRACTICE AND PRACTICAL STANDPOINT IN MARX}

\section{José Crisóstomo de Souza}

Based on Marx's Theses ad Feuerbach and German Ideology, and on views of Peirce, James and Dewey, the paper critically examines the notions of practice and practical materialism in Marx, in relation to their convergence but also difference with classical North-American pragmatism, On one side, it highlights the virtues of Marxian notion of practice and reality as sensuous activity, for a renewed understanding of notions such as reality, objectivity and knowledge, and, on the other, calls attention to possible essentialist and 'transcendentalizing' elements in Marx's thought that may have marked negatively his whole mature theory.

KEY-worDS: Practical materialism. Pragmatism. Sensuous activity. Reality. Knowledge.

\section{A PROPOS DE LA PRATIQUE ET DU POINT DE VUE PRATIQUE CHEZ MARX}

\section{José Crisóstomo de Souza}

Le texte parle des notions de pratique et de matérialisme pratique chez Marx dans une relation de rapprochement et de distinction avec les conceptions du pragmatisme classique nordaméricain à partir des thèses de Feuerbach et de l'Idéologie Allemande de Marx ainsi que des formulations de Peirce, James et Dewey. D'une part, il met enévidencela fécondité de la notion marxienne de pratique et de réalité come activité sensible pour une interprétation renouvelée de notions telles que la réalité, l'objectivité et la connaissance et, d'autre part, il attire l'attention sur de possibles éléments essentialistes et transcendantalisants dans la pensée de Marx qui marqueraient de manière négative l'ensemble de son œuvre.

Mots-CLÉs: Matérialisme pratique. Pragmatisme. Activité sensible. Réalité. Connaissance.

José Crisóstomo de Souza - Doutor em Filosofia. Pós-doutorado em Filosofia. Professor do Depto. de Filosofia da UFBA. Principais áreas de interesse: filosofia contemporânea, pragmatismo, neo-hegelianismo, Marx, crítica da modernidade, filosofia política e social, democracia. Publicações recentes: Teses de Marx: para uma Crítica ao (Não-)Pragmatismo de Marx. Cognitio, São Paulo, PUCSP, v.13, p.115-144, 2012; A virada práticohistórica da filosofia: Hegelianismo, Pragmatismo, Pluralismo, Democracia. Salvador: Edufba, 2012. v.1. $154 \mathrm{p}$ 